\title{
Una historia relacional: masones, redes y sociabilidad entre Canarias y América
}

\section{Valeria Aguiar Bobet}

\section{(2) OpenEdition}

1 Journals

Edición electrónica

URL: https://journals.openedition.org/cher/530

DOI: $10.4000 /$ cher.530

ISSN: 2803-5992

\section{Editor}

Presses universitaires de Strasbourg

\section{Edición impresa}

Fecha de publicación: 10 junio 2021

Paginación: 125-152

ISBN: 9791034400928

ISSN: 1968-035X

\section{Referencia electrónica}

Valeria Aguiar Bobet, «Una historia relacional: masones, redes y sociabilidad entre Canarias y América», reCHERches [En línea], 26 | 2021, Publicado el 13 octubre 2021, consultado el 17 noviembre 2021. URL: http://journals.openedition.org/cher/530 ; DOI: https://doi.org/10.4000/cher.530 


\title{
Una historia relacional: masones, redes y sociabilidad entre Canarias y América
}

\author{
Valeria Aguiar Bobet*
}

$\mathrm{L}$ a masonería se ha estudiado en los últimos años como una de las primeras instituciones globalizadas y globalizadoras de la historia, como una de las asociaciones con mayor difusión de las ideas de la modernidad, prácticas de sociabilidad y trasvase de personas por todo el planeta. Un trasvase que ha generado toda una serie de redes, interconexiones, solidaridades e intercambios de ideas, prácticas, lenguajes, etcétera. En otra ocasión (Aguiar Bobet 2018: 56-92), tuvimos la oportunidad de estudiar, a partir del análisis de redes epistolares, los vínculos establecidos entre la masonería hispano-marroquí y la latinoamericana durante la II República española (1931-1936) bajo este mismo prisma «global». Fundamentalmente, cuantificamos y calificamos diversos ítems de la red establecida y llegamos a varias valoraciones interesantes como la asiduidad de los contactos, su importancia en relación con la menor proporción que presentaban otros contactos con masonerías más cercanas, el lenguaje de solidaridades masónicas derivadas de la nueva situación republicana española y de las jóvenes repúblicas americanas, así como la indiscutible identificación de las masonerías implicadas a través del topos de la madre patria que representaba España.

En esta ocasión, si bien pretendemos ahondar en algunos de estos ítems, nuestro eje se ajustará a las relaciones entre masones que pulularon entre Canarias y América y que, además, tendrán un contexto muy diferente al anterior hispano-marroquí al que nos hemos referido anteriormente: al excluirse el carácter colonialista de las masonerías en juego y añadiendo la importancia migratoria canario-americana, la red de relaciones masónicas configurada por un grupo significativo de individuos en Canarias durante el siglo XIX y principios del $\mathrm{xx}$, procedentes o con destino hacia América, se encontraría inmersa en el mismo entramado global de redes y sociabilidad del Arte Real. El

* Valeria Aguiar Bobet, Universidad Jaume I/ Universidad de La Laguna. ORCID: 00000001-7343-5169, <vaguiar@uji.es>. 
archipiélago canario, llamado comúnmente «las Islas», bajo este macro-análisis, constituyó un espacio de tránsito, de destino y de partida; un espacio en el que las logias y organismos intermedios de potencias masónicas, cuya sede central se encontraba en Madrid o Lisboa, actuaron como enlace entre las élites locales, los migrantes y los extranjeros de paso.

Las situaciones de contacto derivadas de esta interacción, inmortalizadas en la correspondencia epistolar masónica y privada, nos han permitido observar la diversidad de funciones que asumieron los actores, los lazos de cooperación, solidaridades y tensiones, pero también cómo se intercambiaron, se negociaron y se difundieron sus diferentes demandas, compromisos, expectativas e intereses. A través de estas redes egocentradas, el asociacionismo masónico y la sociabilidad consecuente, nuestro interés, por tanto, se encuentra en construir una connected history; una historia relacional que es, de algún modo, local, nacional y mundial, en la medida en que estos individuos interactuaron simultáneamente: al operar desde la masonería y desde Canarias en diversas esferas (la economía, la sociedad, la política, la cultura...), las conectaron y revelaron cómo se conectaron entre sí.

De este modo, en las líneas que siguen abordaremos el espacio canario y masónico desde las diferentes categorías que propone el análisis relacional en cuanto a los actores como eje central, la construcción de los espacios, las redes y las prácticas de sociabilidad generadas. En otras palabras, una historia focalizada en los protagonistas, pero también en Canarias como un espacio de ida y vuelta, como enclave de tránsito; $\mathrm{y}$, a su vez, una historia focalizada en la percepción de los diferentes países americanos y de América por parte del conjunto de actores que, en sus periplos vitales, se relacionaron con logias masónicas de ambos lados del Atlántico. También los talleres, la práctica de la masonería desarrollada en ellos, serán otro de los aspectos que pretendemos abordar desde los protagonistas efectivos y significantes de estos espacios, espacios a la vez materiales y simbólicos, espacios que adquieren un determinado lenguaje político-social, unas formas concretas de sociabilidad; espacios en los que, por último, se conforman y construyen identidades colectivas, sociabilidades y todo tipo de interacciones sociales.

En definitiva, los participantes de estas redes serán analizados en calidad de actores, en calidad de productores de su historia. Aquellos que, a través de la correspondencia masónica y privada $-\mathrm{y}$ otras fuentes generadas por la orden-, nos han mostrado cómo utilizaban estos espacios, los vínculos masónicos y sociales recreados en ellos, cómo los percibían y cómo percibían, a su vez, las propias Islas, la situación de los países americanos, especialmente Cuba, y la masonería.

Dada la complejidad histórico-antropológica del tema/enfoque que queremos abordar, es necesario, antes que nada, afrontar las disquisiciones teóricometodológicas que nos han llevado a la determinación de configurar este paisaje concreto desde una historia conectada y desde una institución que ha ido a la vanguardia de «lo global». 


\section{Formas de hacer Historia: sociabilidades, Global History y Connected History}

Desde hace algunos años, los especialistas en la historia de la masonería hemos remarcado la importancia de hablar del término en su forma plural y, más que eso, de abordar cada una de las masonerías no solo desde su trayectoria institucional sino desde la producción documental personal y privada de sus miembros: los certificados de viaje expedidos para visitar otras logias de diferentes países; la correspondencia mantenida entre componentes, más allá de los talleres próximos o de la misma obediencia; los garantes de amistad entre diferentes talleres nacionales e internacionales; así como las características inherentes de la orden en cuanto a su cosmopolitismo y a su necesidad expansionista en un periodo donde se iniciaron los imperialismos, la colonización, los procesos de emancipación colonial y, también, los primeros ecos de una incipiente globalización, tal como la conocemos hoy. Es más, parte de esta reivindicación hacia las fuentes históricas generadas por las diferentes masonerías y sus protagonistas ha sido ya tratada en otros lugares (Martínez Esquivel 2018: 1-18), precisamente con el objeto de presentar a esta sociedad desde sus rasgos flexibles y camaleónicos (espacial y temporalmente), y así acabar con ese cierto ostracismo al que le subyuga la academia y sus contrarios, los valedores de las tesis complotistas. La realidad, mucho más compleja, nos ha demostrado que las posibilidades de las fuentes producidas por las masonerías son más amplias y heterogéneas. Como cualquier documento histórico, son susceptibles de ser analizadas bajo diferentes enfoques metodológicos: desde la sociabilidad, las redes sociales, las redes egocentradas o la prosopografía hasta los métodos, cada vez más habituales, de la Global History o de la Coneccted History.

Con el pretexto del presente número de la revista Recherches, protagonizado, por un lado, por la situación excepcional, por así llamarla, de las islas Canarias -en cuanto al trasvase de personas y en cuanto a su situación geoespacial-, y, por otro, por los estudios de la sociabilidad agulhoniana, queremos aprovechar la oportunidad de conjugar ambas variables desde las fuentes masónicas.

Las logias como espacios de sociabilidad formal, pues se trata de una asociación o de una sociedad semi-cerrada (Bryon Portet 2013), han sido estudiadas, entre otros, por Luis P. Martín (2003: 523-550). También ha sido objeto de estudio por parte de la historiografía francesa, por ejemplo, los estudios de Céline Sala sobre la masonería en Perpiñán (Sala 2010: 3-16) o los de Pierre-Yves Beaurepaire respecto al siglo XviII en Europa (Beaurepaire 2013: 2-13). El propio Maurice Agulhon dedicó alguno de sus estudios a tratar el tema (Agulhon 1977), así como Eric Hobsbawm en Rebeldes Primitivos (Hobsbawm 1983: 234-246) y George Simmel respecto a la relación entre sociabilidad y el secreto masónico característico de su condición iniciática (Simmel 1999). En estos estudios, y en otros que por razones de espacio no se citan aquí, se observan las logias como espacios de sociabilidad pluriformal en los que sus componentes están preocupados por responder a las expectativas de las élites 
europeas, así como de otros grupos mediano-burgueses (en función de la dinámica y composición de los talleres). Las logias aseguraron, desde estos análisis, un auténtico renacer social, incluyendo en ocasiones un reclutamiento mixto, además de teatros de sociedad, conciertos amateurs, gabinetes de lectura, bailes, conferencias, acciones de beneficencia. Los escritos personales, también llamados ego-documentos (Beaurepaire y Taurisson 2003: 10-20), dan testimonio de la «masonería en sociedad» y de sus relaciones precoces o constantes con otras sociedades. Muestran también a los viajeros o masones de paso que aprovechan estas redes y contactos como refugio o apoyo, subrayando la importancia del lazo masónico por diferentes diásporas (jacobinas, hugonotas, expatriados) o situaciones coloniales (los judíos sefardíes en las logias hispanas de Marruecos o Salónica, los turcos en las logias italianas). El espacio masónico y el espacio profano, más que confundirse, se interrelacionan indistintamente en función de los intereses y necesidades de sus protagonistas. Tal y como apuntó Agulhon (1977: 5-6), la logia masónica se inscribe y florece en el interior de la oferta de sociabilidad, recomponiéndola sin desgarrarla. Compitió, de este modo, con otras confraternidades, pero permitiendo igualmente adaptarse a las exigencias del "comercio de sociedad» (Agulhon 1977: 6). El estudio de las prácticas de sociabilidad y la reflexión sobre cómo los contemporáneos pensaban el vínculo social, percibían su espacio relacional y vivían sus relaciones interpersonales y las estrategias subyacentes forman parte de este modelo de pensar la historia. El enfoque reside no solo en las prácticas interpersonales de forma aislada, sino en los individuos, en sus interferencias, intercambios, afirmaciones y consolidaciones de poder (Sala 2010: 15). La masonería se exhibe, así, como un espacio de conexión entre diferentes sociedades al mismo tiempo.

En cualquier caso, estos estudios ofrecen una mirada «hacia dentro» de las prácticas masónicas entre los miembros, estudios que se contrapondrían a otros que focalizan la mirada "hacia fuera» de la práctica social de las masonerías, como son los estudios de redes sociales (Martínez Esquivel 2018: 1-18), de redes ideológicas (Mollés 2013: 188-196), económico-comerciales (Saunier 2017: 76-90), o aquellos centralizados en la globalidad de la masonería, en los que se plantea la existencia de un «sistema mundo masónico» (Mollés 2013: 190), una «república universal de francmasones» (Beaurepaire 1999), o la tesis que sitúa al Arte Real como la primera institución en operar a escala global (HarlandJacobs 2017: 65-93). En este tipo de investigaciones, el punto de mira se sitúa en las redes establecidas por las obediencias y logias masónicas, que instauraban de forma continua y constante relaciones formales con otros talleres locales, regionales e internacionales. Estas relaciones les otorgaban reconocimiento y legitimidad externa, además de crear lazos fraternales, ideológicos y todo tipo de interconexiones y comunicaciones. La propia organización piramidal de la orden favorecía el desarrollo de este ensamblaje por medio de la figura de los visitadores, así como el obligado mantenimiento de la correspondencia y la circulación de boletines, revistas o trabajos, cuyo tráfico producía multitud de redes, redes donde circulaban personas, pero, sobre todo, ideas, ideologías, 
tendencias... Estas redes, además, se construían a partir de una serie de criterios y características: según el territorio, las diplomacias y la política, en sentido general, de la propia obediencia o la logia en cuestión, y se manifestaban en diferentes procedimientos: planchas (cartas), viajes, visitas y garantes de amistad. Entre ellos, la correspondencia epistolar es la fuente documental principal para revelar todo este tipo de interacciones entre diferentes talleres, más allá de las formalidades propias de los garantes de amistad y a pesar de las vinculaciones directas con motivo de viajes y de los visitadores. El análisis de la correspondencia, en este sentido, se muestra esencial a la hora de establecer las valoraciones y la magnitud de la red o las redes establecidas. Las cartas informan de relaciones efectivas, vínculos nominales, contenidos y atributos, del mismo modo que muestran su funcionalidad operativa real y revelan la globalidad de sus dimensiones. Y, a su vez, la secuencia cronológica que abarcan muestra la evolución de las relaciones, sus regularidades y variaciones, su renovación y durabilidad, así como la pervivencia de las redes en relación con la propia historia de los actores, de las logias y de sus contextos. De todos modos, el conjunto de la documentación generada por el Arte Real revela valiosa información sobre las prácticas sociales de los actores.

Por otra parte, este enfoque exige también un encuadre global de relaciones francmasónicas que muestre el mapa geocultural y geopolítico de los vínculos, insertándolos así en las redes masónicas internacionales. Este aspecto es imprescindible si tenemos en cuenta que las relaciones y todas las redes, en general, están insertas dentro de un marco más amplio, global, denominado sistema-mundo masónico por algunos autores (Mollés 2013: 188-189), como antes mencionamos. Un régimen propio que, si bien parte de la conceptualización del sistema-mundo moderno defendido por Immanuel Wallerstein, se configura, más bien, dentro de la cosmovisión contemporánea que comienza a discurrir y ordenar, precisamente, una red de interrelaciones globales, es decir, que se inserta en el proceso tan debatido en la actualidad como controvertido, conocido como globalización (Harland-Jacobs 2017: 65-75). En esta cosmovisión, los ideales y preceptos masónicos, tales como la fraternidad, la igualdad entre pueblos, razas y naciones, la solidaridad internacional, etcétera, producen los mecanismos de solidaridad y sociabilidad precisos para establecer diferentes redes e interconexiones con distintos contenidos y significantes. Pero, más que eso, producen la interconectividad del mundo a partir de preceptos comunes, de la comprensión del mundo no solo en su concepción global, sino según unos mismos parámetros que coinciden desde lo local y particular hasta lo internacional y general. Y todo ello en un contexto incentivado por las conexiones entre actores o asociaciones en las cuales convergen múltiples naciones, instituciones y sujetos con intereses, ideologías y objetos comunes. Así, los individuos o logias pueden ser tomados como actores de una historia global en la medida en que, a través de sus acciones y relaciones se percibe la articulación social entre sectores de actividad, espacios o esferas. Además, pueden entenderse como parte de un ensamblaje mayor, nunca individualmente 
o de forma segmentada, por lo que los resultados son siempre indicadores de tendencias, más que estadísticas y datos cuantitativos incuestionables.

No obstante, los diferentes estudios citados, en mayor o menor medida, han sido abordados desde una perspectiva sincrónica y no tanto diacrónica, con el objeto de observar las dinámicas internas y los contactos externos de las logias en uno o varios espacios elegidos como objeto de estudio, y así observar la red de relaciones entre miembros, o entre masonerías en un momento o periodo concreto, siguiendo los planteamientos, por lo general, de la Global History, de la prosopografía o la sociabilidad. Sin embargo, la diacronía o, al menos, el análisis diacrónico de estos procesos en un cómputo de tiempo más amplio y no circunscrito a un periodo predeterminado (siglo XVIII o XIX, la crisis del 98, la II República española, etcétera), no se ha tenido tanto en cuenta por motivos metodológicos, lo que limita algunas de las valoraciones y conclusiones de las muestras, sesgando en cierto modo las historias narradas y, con todo, la evolución y el desarrollo de las propias prácticas de sociabilidad, las redes o relaciones que se pretendían tratar. Por otro lado, también encuentran deficiencias en cuanto a la muestra, pues se centran, sobre todo, en las redes o prácticas sociales como un objeto histórico en sí mismo, más que en los propios individuos. Sin olvidar, entre otras objeciones, la vinculación entre la Global History y las tendencias neoliberales y globalizadoras del presente, que más que producir anacronismos, dejan a un lado otros procesos locales o «micro» que subyacen en/bajo/tras la escala global. Si bien ha sido un tipo de historia que ha roto con las escalas nacionales, tampoco carece de sus propios límites conceptuales.

En este sentido, se puede utilizar la información masónica para algo más que para establecer y confirmar redes ideológicas, personales o globales -sean dentro de un mismo grupo o en sus vínculos externos-, o para analizarlas en sí mismas. La documentación generada por los actores permite también analizar la parte discursiva, las analogías entre los individuos, sus percepciones, autopercepciones y contradicciones. De hecho, se puede utilizar para construir la historia según ellos la experimentan y teniendo en cuenta sus limitaciones y extralimitaciones. De ahí la propuesta del historiador José María Imízcoz sobre la necesidad de construir un «análisis relacional» a partir de la Connected History y partiendo del estudio de las redes egocentradas (Imízcoz y Arroyo 2011: 98-110). Se trata de una combinación de los últimos estudios de Agulhon sobre la sociabilidad, particularmente en Historias vagabundas, que resitúa en el centro de la historia a los actores (Agulhon 1988) para determinar cómo producen y construyen sus historias, sus redes, sus vínculos y sus prácticas de sociabilidad a partir de los documentos personales que nos han legado, especialmente la correspondencia; y más que eso, cómo conectan las diferentes escalas en las que se desenvuelven. Marc Bloch y E. P. Thomson, entre otros, ya habían señalado tal puntualización en varias de sus disertaciones, pues son los individuos los que producen $-y$ nos dan las claves- de los momentos y los lugares en los que vivieron, de las conexiones establecidas y de cómo percibieron sus propias historias (Bloch 1952; Thomson 1989). En este sentido, la historia que nos plantea Imízcoz no trata de 
cuantificaciones, ni de densidad de los nodos o la frecuencia de los contactos, tampoco de abusar de la dialéctica de lo local y lo global, pues no son dos escalas autónomas. Al contrario, están conectadas (o no) por actores que interactúan simultáneamente en ellas y cuyas interacciones producen consecuencias en ellas. No es necesario renunciar a la definición de escalas de observación (local, nacional, global) ni a la articulación de los análisis de un estudio «micro» y «macro», sino que lo relevante es seguir a los actores para percibir, desde sus interacciones, cómo se conectan entre sí y, con ello, cómo conectan las diferentes esferas y escalas en las que interactúan.

Bajo este enfoque metodológico centrado en los discursos y en las personas (y no tanto en las redes en sí), por tanto, se puede establecer la «economía moral» con la que los sujetos interactúan, esto es, los valores con los que plantean sus expectativas, formulan sus demandas, cumplen o no con sus compromisos y juzgan el comportamiento propio o ajeno. Se trataría de construir el desarrollo de la acción visto desde sus propios protagonistas, cómo hacen su historia efectiva, cómo la producen, mueven, resisten o enfrentan con los múltiples elementos que permiten entenderla y explicarla desde dentro: quiénes, cómo, en qué contextos, con qué apoyos, con qué contradicciones, con qué resistencias, con qué ritmos, con qué causas y sentido, con qué efectos.

En el siguiente apartado, por tanto, pretendemos configurar, a modo de aproximación y experimentación, una historia relacional a partir de una muestra más o menos representativa de masones insertos en las redes del Arte Real canario, ibérico, español y americano. La finalidad, en este primer estudio, será determinar cómo los protagonistas seleccionados conectaron las esferas de actuación desde la masonería, cómo entendían el espacio simbólico de las logias canarias y las prácticas sociales, redes ideológicas, etcétera, que produjeron a través de ellas. Bajo un enfoque centrado en los actores pretendemos, con todo, dibujar un paisaje conectado y global de interconexiones y desconexiones, de percepciones y autopercepciones, que tienen varios ejes en común: las formas de relaciones en las logias de diferentes masones a lo largo de la historia de la orden en Canarias, sus vínculos con otras americanas y todas aquellas preocupaciones e intereses que nos brinda la documentación que nos han legado.

\section{Historias (des)conectadas: redes, espacios y sociabilidades masónicas en Canarias}

La muestra que hemos elegido para exponer el paradigma teóricometodológico planteado se compone de 26 individuos no necesariamente relacionados entre sí a título personal, temporal o local ${ }^{1}$. La correlación que

1 Para evitar constantes repeticiones en las citaciones de los expedientes personales, expondremos en esta nota cada una de las referencias consultadas de la muestra. Solo en las ocasiones necesarias se citarán de forma concreta. Los expedientes personales masónicos consultados se encuentran en el Centro Documental de la Memoria 
sustenta su elección se debe a que todos ellos estuvieron afiliados a logias masónicas situadas en Canarias y tuvieron algún tipo de vinculación, fuese por medio de la masonería o por cualquier otra circunstancia, con algún país latinoamericano, especialmente Cuba y Venezuela, dados los lazos indiscutibles de la migración canario-americana a estos países entre los siglos xix y xx (Pomares y Aguiar 2017: 25-20). Esto implica que el análisis de los individuos no se centrará, exclusivamente, en las redes interpersonales o egocentradas entre ellos, sino que cada uno, de forma más o menos aislada, pero con puntos de conexión, nos ofrece desde su situación canaria o americana y desde cómputos de tiempo diferenciados (desde los años 60 de la centuria decimonónica hasta los inicios de la guerra civil española), las prácticas asumidas en la masonería como asociación formalizada, las funciones que según sus percepciones debía asumir la orden, sus intereses, deseos y decepciones y, por último, las redes establecidas con otros masones, con otras masonerías y con otros grupos o instituciones a ambos lados del Atlántico. En otras palabras, los elementos en común en esta muestra diacrónica y geoespacial, protagonizada por diferentes individuos, son transversales, de tal modo que podamos observar las continuidades, los cambios, las conexiones y desconexiones de los diferentes actores en y desde la masonería, en y desde Canarias.

Para ello, ofreceremos al lector, en primer lugar, un análisis general del conjunto, esto es, los aspectos generales de los actores (las fechas en las que ingresaron en la masonería, la procedencia, las profesiones, los rangos y el estatus social), y, en segundo lugar, los aspectos generales masónicos (los grupos de edades durante su estancia en la masonería, los grados adquiridos, las logias y obediencias a las que pertenecieron, los nombres simbólicos); combinados ambos ítems con los intereses, redes, otras prácticas e informaciones de interés, especialmente aquellos puntos de encuentro $-\mathrm{y}$ desencuentro- entre unos y otros.

Histórica (CDMH), Sección Especial Masonería A: José Cabrera Díaz carpeta (c.) 99 expediente (exp.) 22; Elías Marrero Gutiérrez c. 45 exp. 22; Ángel Possentini c. 48 exp. 2; Cándido Alarcó Aznar c. 38 exp. 14; Silvio Montero Paullier c. 122 exp. 14; Manuel García Hernández c. 252 exp. 48; José María Alonso Gutiérrez c. 38 exp. 21; Pedro Rodríguez Rodríguez c. 49 exp. 11; Domingo Marrero Rodríguez c. 45 exp. 25; Antonio García González c. 36 exp. 5; Tomás Sanjuán Jesús c. 104 exp. 7; Francisco Hernández Hernández c. 186 exp. 6; José Ma Mendoza Santana c. 496 exp. 54; Tomás Acosta c. 580 exp. 14; María Macías de Parés c. 45 exp 8; Tomás Pérez Morales c. 103 exp. 4; José Ruiz Rodríguez c. 49 exp. 23; Melitón Gutiérrez Castro c. 43 exp. 29; José Ma Mendoza Pérez c. 109 exp. 5; Ramón González del Socorro c. 580 exp. 19; Diego Ponte del Castillo c. 120 exp. 11; Patricio Estévanez y Murphy c. 326 exp. 47; Luis Dugour y Ruz c. 41 exp. 26; Ramiro Dugour y Ruz C. 436 exp. 55; Miguel B. Espinosa de los Monteros c. 696; José Gomido Sunior c. 122 exp. 14 (sus datos aparecen en el expediente personal de Silvio Montero Pauillier). 


\section{Aspectos generales de la muestra}

La muestra elegida está compuesta, como hemos señalado anteriormente, por 26 individuos de procedencia y cronología dispar. Si bien todos ellos, incluida una mujer, nacieron entre los años 40 y 90 del siglo XIX, su estancia en la masonería, por motivos de edad, osciló entre el periodo previo al Desastre del 98, es decir, la etapa que marca el final de la «edad de oro» del Arte Real español, y los treinta primeros años del siglo $\mathrm{xx}$, que, a su vez, presenta diversas etapas determinadas por los distintos periodos políticos de la historia de España y de la orden (crisis de la Restauración, dictadura de Primo de Rivera y II República). Catorce son españoles, doce de ellos canarios, y el resto está conformado por ocho cubanos, un venezolano, un uruguayo, un brasileño y un italiano. Todos estuvieron afiliados a logias canarias en algún momento de su trayectoria vital y en diez casos, con seguridad, se iniciaron o continuaron su andadura masónica en Puerto Rico, Montevideo, La Guaira y, sobre todo, en diferentes ciudades de Cuba, particularmente, La Habana. Para el resto de los sujetos de la muestra, de una u otra manera, consta información relativa al cambio de residencia o la estancia en algún país americano por motivos varios (emigración, participación en la guerra de independencia de Cuba o en la guerra civil de 1936), escritos, publicaciones, garantes de amistad, actividades políticas, o bien cierta vinculación ideológica hacia «América», en relación con el topos de la madre patria, como veremos más adelante.

Las profesiones o cargos que ocuparon variaron: desde comerciantes (6), tipógrafos y periodistas (3) -en los tres casos asociados- propietarios (2), cónsules (2), marinos (2), empleados (2), médicos (2), hasta un periodista, un jornalero, un maestro de obra, un tabaquero, un consignatario, un moldeador y un marqués-propietario. La mujer masona, por su parte, añadió la expresión habitual de la época para denominar su ocupación doméstica: «su sexo». Si bien los nombres de las profesiones siempre resultan poco categóricos, se observa, según la descripción ofrecida por sus protagonistas, que el porcentaje mayor recae en la pequeña-mediana burguesía adscrita al comercio y a las profesiones liberales, en detrimento de las élites con mayor renombre de las Islas y los grupos obreros. En tal caso, la presencia de Diego Ponte del Castillo (18401880), VIII marqués de la Quinta Roja, dentro del conjunto, una personalidad de renombre en la historia de Canarias, así como la presencia del jornalero y el maestro de obras, presentan los extremos sociales de las diferentes logias masónicas y de los diferentes periodos de la orden, tal y como sucedía en otras zonas, hecho este estudiado detalladamente por Manuel de Paz en su tesis doctoral sobre la Francmasonería en Canarias (De Paz 2008). Tal vez, el término apropiado para agrupar a la muestra sería el de una incipiente «élite local» que, tal y como su nombre indica, representaría a aquellas personalidades con mayor peso e influencia política y socio-económica de los municipios. Una élite más bien variopinta que, con todo, se encontraba a la vanguardia del resto de la población, de mayoría analfabeta y circunscrita a las desavenencias de la clase 
trabajadora en las ciudades portuarias y al caciquismo imperante en las zonas rurales. Uno de los individuos de la muestra, Melitón Gutiérrez Castro (18781936/8), reflejaría parte de esta condición en una obra publicada en Santa Cruz de Tenerife: Los incognoscibles ${ }^{2}$, en la que retrata la miseria de las gentes de la ciudad portuaria, su ruda brutalidad y la triste lucha por la supervivencia en su habitual cotidianeidad.

No obstante, lo más interesante de la composición socio-profesional aquí indicada, ha sido la heterogeneidad entre los individuos en cuanto a su reconocimiento desde el ámbito de la Historia, es decir, algunos de los actores incluidos fueron, y siguen siendo, célebres personajes de la identidad comunitaria del Archipiélago, mientras que los demás son apenas conocidos. Nos interesa bastante este punto por la carga simbólica que presentan unos en contraposición al grupo más frecuente de hombres y mujeres «desconocidos». Las analogías que se apreciarán al final de este recorrido serán una de las claves esenciales para sopesar el espacio de la logia desde el punto de vista de la sociabilidad y las redes establecidas, así como para valorar, desde diferentes perspectivas, la percepción de la masonería canaria, entre otros factores, por parte de sus variopintos protagonistas.

Entre los personajes más conocidos se encuentra el mencionado Diego Ponte del Castillo, marqués de la Quinta de Roja. La influencia del marqués en el Arte Real canario, que incluye la expansión y consolidación de la masonería en la isla tinerfeña, es una muestra representativa de la importancia de la orden para un sector de la élite local canaria de raigambre liberal, contraria al peso del clericalismo, que buscaría en sus filas y en sus espacios, formas alternativas de la práctica social, tanto para reforzar sus ideologías y las redes interpersonales como sus intereses más allá de la logia, las solidaridades en común, etcétera. Manuel de Paz, a este respecto, señala cómo durante este periodo, especialmente durante el Trienio Liberal, las logias, concentradas sobre todo en Tenerife, conseguirán dar algunos frutos sociopolíticos (De Paz 1991: 755-758). De hecho, la represión que se cerniría sobre los talleres canarios y españoles con el retorno de Fernando VII, aunque consiguió frenar las actividades masónicas, no las destruiría por completo. El pronto fallecimiento del marqués (el 4 de abril de 1880) y la negación de su sepultura sagrada por la intransigencia clerical de la época producirían no solo una de las historias más representativas de la condena de la masonería en España, sino uno de los monumentos más simbólicos de la masonería canaria. Su madre, Sebastiana del Castillo, erigiría un mausoleo, que aún se eleva en el valle de La Orotava, en los comúnmente llamados Jardines Victoria. El monumento representa, por un lado, la compensación de la injuria que la intolerancia religiosa infirió a la masonería y a su partícipe, quien había pertenecido a las logias Taoro $n^{\circ} 90$ del mencionado municipio (logia que fundó

2 La obra fue publicada con el pseudónimo Calícrates Temísdemos, pero su autoría corresponde a Melitón Gutiérrez Castro. Fue publicada en la Biblioteca Violeta en 1908, propiedad del propio autor, que era tipógrafo, y de su compañera sentimental. 
y que adoptó como nombre su propio nombre simbólico), Teide no 53 de Santa Cruz y, previamente, a Afortunada, no 36 de Las Palmas de Gran Canaria, en torno a 1870, siendo posible que fuera iniciado en Francia, donde residió algún tiempo. Ponte había colaborado, a su vez, con otros procesados por la misma razón (De Paz 2008, vol. 1: 317). Además, es una muestra significativa de arte y símbolos masónicos, elaborado bajo la dirección del arquitecto francés Adolph Coquet (De Paz 2007: 300-310).

Otro de los célebres partícipes de la muestra, José Cabrera Díaz (18751939), «un canario al servicio de Cuba»-como lo han descrito algunos autores (González Díaz 2010: 2-3)-, fue un ilustre periodista canario que inicia su labor colaborando con los sectores republicanos y obreristas de Tenerife, publicando en diferentes periódicos y revistas, denunciando al Ejército español en la guerra declarada a los pro-emancipadores de Filipinas y Cuba. También entre otras iniciativas, colabora en la creación de la Biblioteca del Obrero, en la que participó también otro de los protagonistas de la muestra, el médico y escritor, Miguel B. Espinosa de los Monteros, así como en otra iniciativa paralela, la Asociación Obrera de Canarias, y su órgano de expresión, el diario El Obrero, que pretendía, al igual que el resto de propuestas, luchar contra las desigualdades sociales en Canarias. José Cabrera, dada su trayectoria turbulenta y sus constantes enfrenamientos con las élites más conservadoras de la isla tinerfeña, se ve obligado a emigrar a Cuba en 1900, donde cofundará el Partido Nacionalista Canario y el Ateneo Canario, y publicará otras revistas ensalzadoras del nacionalismo del Archipiélago. Su estancia en la masonería, de apenas un año, refleja la ambivalencia de sus discursos al someter al taller al grito de Yara, mediante una mezcla simbólica de amor a la patria, anticolonialismo antillano y de nacionalismo canario incipiente, producto de tales desavenencias y recorrido vital (De Paz 2009: 45-56).

Por otro lado, también se ha incluido a Patricio Estévanez y Murphy (18501926), quien fue periodista y literato, así como un republicano convencido, que ejerció una notable influencia en la política y la sociedad canaria. Defensor incansable de Tenerife en la denominada «cuestión del pleito insular», llegaría al grado $18^{\circ}$ en la masonería, siendo uno de los más destacados dirigentes de las logias Hijos del Teide $\mathrm{n}^{\circ} 94$ y Tinerfe $\mathrm{n}^{\circ} 114$, ambas con sede en la capital santacrucera. A la segunda también estaría asociado un órgano de prensa, que compartía el nombre del taller, bajo su dirección. En paralelo, fue director de la Ilustración de Canarias entre 1882 y 1884 y del Diario de Tenerife entre 1886 y 1917; y, a su vez, consejero electo del primer Cabildo tinerfeño en 1913 y promotor del Hospital de Niños propuesto por el doctor Guigou. Patricio Estévanez, hermano del también ilustre Nicolás Estévanez y Murphy, formaría parte de la élite canaria desde finales del siglo XIX, en gran medida contraria al autonomismo de $\mathrm{Cuba}^{3}$ (De Paz 2006b: 18), nada comparable a las posturas

3 En una carta que le remite Miguel Villalba Hervás, le critica precisamente esta postura hacia el autonomismo cubano, que consideraba que podía acelerar el proceso de emancipación de la isla antillana, 31 de octubre de 1897. 
más radicales de José Cabrera Díaz o, como veremos a continuación, de otros protagonistas de la muestra.

En segundo lugar, como parte de un grupo de personalidades también de cierta importancia política y literaria, aunque menos conocidas, que han sido estudiadas, en algunos casos, por diferentes historiadores, se encuentran en la muestra el citado periodista y tipógrafo Melitón Gutiérrez Castro (De Paz 2018; Aguiar Bobet 2014), el médico y escritor Miguel B. Espinosa de los Monteros (De Paz, Luis y Aguiar 2020), Luis Dugour y Ruz y Ramón González del Socorro.

Gutiérrez Castro, quien también firmaría en numerosos artículos de periódico con el pseudónimo El Curioso impertinente, había nacido en Toledo, pero, por avatares de la vida, después de su participación en la guerra de Cuba como sustituto, se asienta en Santa Cruz de Tenerife, donde ejerce como tipógrafo y periodista. Destacado anarquista, nos ha legado también varias obras de carácter literario en las que denuncia las atrocidades sufridas por el Ejército español en Cuba (Seis horas en campaña), otra en la que narra la cruda realidad de las capas más bajas de la capital portuaria en la que reside (Los incognoscibles), su colaboración en varios semanarios satíricos (El moscardón, entre otros) y su participación en la prensa grancanario-tinerfeña de principios del siglo xx. Su actividad política-periodística lo llevaría a diferentes enfrentamientos con las élites de la zona, hasta el punto de mudarse a la isla vecina, Gran Canaria, e incluso de acabar procesado en varias ocasiones. De todos modos, su andadura terminaría chocando irremediablemente con el «Glorioso Movimiento Nacional», por el que sería represaliado. Su estancia en la masonería, en la logia Añaza $n^{\circ} 125$, tan corta como la de José Cabrera Díaz, dejaría, sin embargo, las huellas necesarias para entender algunas de las características de la institución, sus redes y su significado en el contexto que abordamos, como seguiremos viendo en los siguientes apartados. En otro lugar (Aguiar Bobet 2014), en el que estudiamos la obra que dedica a su experiencia en la guerra de Cuba, pudimos observar cómo su estancia en Canarias, después de la contienda, determinó su percepción de los acontecimientos narrados -bastante crudos en opinión de Nicolás Estévanez, el prologuista de la obra-, una percepción favorable, como en el caso de Cabrera Díaz, de la emancipación cubana, de la libertad de los pueblos y de los individuos, y contraria, por ende, al terrible sufrimiento y maltrato experimentado por los soldados españoles en el Ejército de la nación (Aguiar Bobet 2014: 180-185). Gutiérrez, integrado en este sentido en la élite local de las Islas, tal vez, si en algo "se equivocó» en su búsqueda incesante de redes y apoyos, fue en su procedencia toledana. Además de las rencillas políticas que le harían obtener más de un enemigo, era "peninsular» y no canario, ni cubano, ni ninguna de las variables con las que se comenzaron a construir, por estas fechas, el «hecho diferencial canario». Tal y como apunta De Paz (2017), Melitón Gutiérrez, en la masonería y en los grupos partidistas del Archipiélago, había dado varios motivos a los poderosos locales para perjudicarlo: primero, por la claridad y veracidad de su prensa (especialmente con motivo de una huelga de trabajadores promovida por las casas carboneras), y, segundo, por su ataque a 
Unión Patriótica (especie de Solidaridad Canaria nutrida de conservadores y radicales), abogando por la formación del partido radical y disgustando a los republicanos. Además, añadiría uno de sus defensores de la logia, Amado Zurita, «es peninsular y aunque para muchos eso no es nada, para algunos espíritus mezquinos es mucho» (De Paz 2018).

Por su parte, Miguel B. Espinosa de los Monteros, recién biografiado por Manuel de Paz y colaboradores en un estudio sobre la Biblioteca del obrero, había nacido en Guanajay (Cuba) en 1838, aunque sus progenitores procedían del Archipiélago. Fue director de La Voz de Taoro (1876-1878), entre otros periódicos, pero, además, compuso poemas, pronunció conferencias y tradujo algunas obras del francés. Falleció en La Orotava en 1898. Alcanzó el grado $18^{\circ}$ del Rito Escocés Antiguo y Aceptado, y ocupó, entre otros cargos, la veneratura de la logia Taoro $n^{\circ} 90$ de la citada villa en 1881, tras la crisis constitucional masónica que acabó con la «década prodigiosa» de la masonería en Canarias. El 18 de marzo de 1883 causó baja en el taller por plancha de quite, como era preceptivo, aunque existen indicios de que pudo retornar por algún tiempo a la actividad masónica, pero, como mucho, hasta finales de 1886. Espinosa de los Monteros había redactado una Memoria en 1876, al objeto de participar en un concurso que había convocado la logia Lealtad de Barcelona, precisamente para combatir a los jesuitas, y que había merecido, en 1877, un diploma de honor. Su colaboración con la Biblioteca de El Obrero nos muestra también sus preferencias ideológicas y la tendencia de cierto sector de la masonería española inclinado hacia la emancipación de este grupo (De Paz, Luis, Aguiar 2020), como ya vimos en casos anteriores y como seguiremos especificando.

En el caso de Ramón González del Socorro, tabaquero de origen canario y miembro de la citada logia Taoro $n^{\circ} 90$ de La Orotava, su relación con América y su protagonismo en esta historia, más que estar ligada a las migraciones canarioamericanas o a la participación en la guerra hispano-cubana, viene determinada, como en otros casos mencionados, por su inclusión en 1892 en el Partido Revolucionario Cubano fundado por José Martí al otro lado del Atlántico. Su figura, poco conocida (De Paz 2004: 265-275), discurre en la misma línea de las demás celebridades mencionadas a propósito de este estudio. Su corta estancia en la masonería, por su partida hacia la Gran Antilla, legaría uno de los discursos más célebres sobre la independencia de Cuba, aunque, también es cierto, en esta etapa de su trayectoria no contradeciría su españolidad ni su «amor a la patria».

En los demás casos, también escasamente conocidos, encontramos a Luis Dugour y Ruz y a su hermano, Ramiro Dugour y Ruz, quienes mantienen contactos importantes con las altas esferas masónicas, especialmente con Francisco Rispá de Perpiñá, miembro del Gran Oriente Ibérico, así como con otras obediencias o logias americanas. Luis Dugour, médico de profesión, presenta una andadura de larga trayectoria en el Arte Real canario, pues pertenecería a distintas logias: Teide $n^{\circ}$ 53, Hijos del Teide $n^{\circ} 94$, Tinerfe $n^{\circ} 114$ y Añaza, no 125, de la que fue fundador. Prácticamente la cronología que ocupa abarca de 1873 hasta su muerte, en 1913. 
Junto a ellos, también constan como miembros de la élite político-local de las Islas dos cónsules: Silvio Montero Paullier y José Gomido Sunior, de Uruguay y Brasil respectivamente, provenientes directamente de tales países, donde también se debieron iniciar en los preceptos del Arte Real (el primero perteneció a la logia Andamana no 3 de Las Palmas de Gran Canaria desde 1931 y el segundo, con seguridad, perteneció a este mismo taller hasta 1936, momento en el que regresó a Brasil). Silvio Montero, además, fue uno de los fundadores de la logia Acacia no 4 del Puerto de la Luz de la ciudad de Las Palmas en 1932, lo que demuestra su grado de compromiso masónico y su consolidación en las redes locales de la Isla, aunque protagonizó algunos pleitos intermasónicos con la logia que primero lo había acogido, pues tildaría a alguno de sus componentes de «vivir del sablazo» y otras expresiones al uso (De Paz 2008 vol. 2: 236). También, junto a otros masones canarios, sería deportado en los primeros momentos del golpe de estado por la policía de los sublevados.

El resto de actores, entre los que se encuentra María Macías de Parés, esposa de uno de los hermanos de Añaza no 125 y, luego, $n^{\circ} 250^{4}$ al cambiar de obediencia, y que forman el grueso de la muestra analizada, nos ofrecen datos relacionados con su estancia en la masonería, además de aquellos señalados en cuanto a procedencia y edad, por lo que serán tratados en el apartado siguiente.

Para terminar de presentar las características y la valoración general de la muestra, cabe mencionar que la tendencia ideológica y asociativa socio-política varía según los individuos. La muestra refleja la heterogeneidad ideológica propia de la trayectoria de la masonería española: unos conjugan posturas más anarquistas y socialistas, mientras que otros son más moderados (republicanos, conservadores, sin afiliación concreta). En algunos también se conjugan ideas autonomistas y nacionalistas, para Canarias o para Cuba, pero en la gran mayoría de los casos prima cierta españolidad (pese a las críticas), un fuerte anticlericalismo, el apoyo a la emancipación obrera -aunque prevalece la tendencia paternalista-conservadora salvo en los casos de José Cabrera Díaz, Miguel B. Espinosa, Ramón González del Socorro y Melitón Gutiérrez Castro- y, sobre todo, una tendencia universal a las ideas liberales propias de la masonería. Los preceptos más elementales del Arte Real -la fraternidad, la igualdad y la libertad-, pero también el cosmopolitismo, los valores democráticos propugnados en ella y el apoyo mutuo interpares se muestran como elementos de unión y de elección para experimentar y disfrutar de los beneficios de la sociabilidad masónica. Es en este sentido, y no tanto en el político-partidista, que al fin y al cabo es el que crea mayor disyunción, en el que los sujetos buscan afiliarse en las logias canarias, ya fuese por haber llegado recientemente a las Islas o por necesidades de afianzamiento social y local. Pero para una comprensión

4 Francisco Parés Llansó, coronel médico del cuerpo de Sanidad Militar, era, al igual que su esposa, gran aficionado al espiritismo, en boga en su época, lo que los llevó a fundar una especie de obediencia masónica ad hoc: la Gran Logia Ángeles, de la llamada Masonería Blanca, Rito de la Verdad, en Santa Cruz de Tenerife. 
mejor de las redes, conexiones y desconexiones, debemos ahondar en las características masónicas de la muestra seleccionada.

\section{Otros aspectos masónicos}

Las logias canarias a las que pertenecieron los sujetos de la muestra se encontraban situadas principalmente en las dos capitales de provincia a partir de la división del Archipiélago en 1927 es decir: en Las Palmas de Gran Canaria (Afortunada $n^{\circ} 36$, Afortunada $n^{\circ} 5$, Andamana $n^{\circ} 3$ y Acacia $n^{\circ} 4$ ) y en Santa Cruz de Tenerife (Hijos del Teide $n^{\circ} 94$, Tinerfe $n^{\circ} 114$, Añaza no 125 y Añaza $n^{\circ} 270$ ), así como en Santa Cruz de La Palma (Abora no 91 y n 331) y otras en el núcleo urbano del norte de la isla tinerfeña, donde se localizaba uno de los municipios con mayor importancia socio-económica de la época además de la capital, La Orotava (Taoro $\mathrm{n}^{\circ}$ 90). Se trataba de áreas con un marcado carácter mesocrático, económico, político y comercial, además de albergar a aquellos individuos con mayor formación educativa; y a la mayor parte de las asociaciones y grupos, más o menos formados, de tendencia ideológicopolítica, sindicales e incluso espiritistas-teístas, tal y como se refleja en otro componente de la muestra, Cándido Alarcó, quien participaba en estos últimos junto con otros miembros de la logia Añaza no 125 y 270 (De Paz 2008 vol. 2: 119), algo habitual y muy a la «moda» en la época (González Fernández 2003: 98). En la ciudad santacrucera, además, existió un capítulo (Añaza no 51 ) y una Cámara Kadosh (Canarias $n^{\circ} 12$ ) a las que pertenecieron algunos miembros aquí tratados, lo que indica el grado de expansión, difusión y consolidación del Arte Real en Canarias. La residencia de los sujetos, por lo general, siempre se encontraba situada en la ciudad de la misma logia.

\begin{tabular}{|c|c|c|c|c|}
\hline Logia & Cronología & Obediencia & Ciudad & $\begin{array}{c}\text { Masones } \\
\text { de la muestra }\end{array}$ \\
\hline Afortunada n ${ }^{0} 36$ & $1870-1887$ & Gran Oriente Lusitano Unido (GOLU) & Las Palmas de Gran Canaria & 1 \\
\hline Teide $\mathrm{n}^{0} 53$ & $1873-1878$ & GOLU & Santa Cruz de Tenerife & 1 \\
\hline Afortunada n 05 & $1888-1896$ & Gran Oriente Nacional de España (GONE) & Las Palmas de Gran Canaria & 2 \\
\hline Abora $\mathrm{n}^{0} 71$ & 1879-1900 & GOLU & Santa Cruz de La Palma & 1 \\
\hline Taoro n ${ }^{0} 90$ & 1874-1878 & GOLU & La Orotava & 3 \\
\hline Hijos del Teide n ${ }^{\circ} 94$ & $1875-1878$ & GOLU & Santa Cruz de Tenerife & 2 \\
\hline Tinerfe $\mathrm{n}^{0} 114$ & 1877-1878 & GOLU & Santa Cruz de Tenerife & 1 \\
\hline Añaza no 125 & $1895-1903$ & Gran Oriente Ibérico (GOI) & Santa Cruz de Tenerife & 13 \\
\hline Andamana $n^{0} 3 n^{0} 1$ & $1922-1936$ & Gran Oriente Español (GOE) & Las Palmas de Gran Canaria & 3 \\
\hline Añaza nº 270 & 1903-1922 & GOE & Santa Cruz de Tenerife & 6 \\
\hline Acacia n ${ }^{0} 4$ & $1932-1936$ & Gran Logia de las Islas Canarias (GLIC)-GLE & Las Palmas de Gran Canaria & 1 \\
\hline
\end{tabular}

Tabla 1. Logias y obediencias canarias en las que participaron los individuos de la muestra

No es nuestra intención hacer una historia de estas logias ni de su recorrido (véase a este propósito De Paz 2008), sino más bien mostrar la diversidad de logias a las que se acogieron, independientemente de la obediencia que las auspiciaba, pues, en función del momento y el lugar, la variabilidad de talleres hizo que los 
individuos pudiesen iniciarse o afiliarse en aquellos donde mayor conexión o relación encontraron (Tabla 1). De hecho, algunos de ellos coincidieron en los mismos talleres y se relacionaron entre sí, aunque el eje más fuerte se concentró en Tenerife, concretamente en la logia Añaza de Santa Cruz. Con vistas a futuros trabajos, habría que aumentar el número de la muestra para ofrecer aquellas variables significativas entre las prácticas sociales e interpersonales de los sujetos en cada una. En todo caso, pertenecer a la masonería y acudir a estos espacios alternativos de la práctica social parecía triunfar sobre cualquier especificidad ideológico-discursiva de las obediencias a las que pertenecían. Solo en dos ocasiones habrá ciertas dificultades que pondrían en evidencia la inestabilidad masónica canaria, directamente relacionada con la peninsular: la crisis institucional acontecida con el Gran Oriente Lusitano Unido, en la que las logias españolas adscritas a este organismo debieron buscar los auspicios de la pluralidad de obediencias hispanas; $y$, a finales del siglo XIX, las desavenencias ocurridas entre el incipiente Gran Oriente Español y el Gran Oriente Ibérico, desavenencias que se reflejan en las continuas cartas de Luis Dugour con Rispá de Perpiñá. Los motivos, más que en relación con el Arte Real, se debían, según ambos, a las ambiciones masónicas de Miguel Morayta, su gran maestre, y a ciertas denuncias de "exclusivismo» del oriente, pero también al hecho de no haber promocionado de forma insistente su denominación «ibérica» ${ }^{5}$.

En el primer supuesto, la falta de dirección y el desconcierto reinante en el seno de la masonería española a mediados del siglo xix hizo que las logias canarias se afiliasen directamente a grandes orientes extranjeros, especialmente al Gran Oriente Lusitano Unido de Lisboa (en 1869), lo que denotaba, una vez más, la importancia de la institución en sí misma, en nada vinculada a preceptos de índole nacional. El resultado fue que, al menos durante diez años, la masonería portuguesa y canaria estuvieron unidas en una prefiguración de Unión Ibérica (Oliveira Marques 1983: 52) y que, en el momento en que tuvieron que decantarse por alguna obediencia hispana, por las propias controversias del oriente portugués, el pluralismo masónico español y su lucha de poder, especialmente en el seno del Gran Oriente Nacional de España (GONE), supondrían la elección del Gran Oriente Ibérico (GOI) del vizconde de Ros (una vez se disuelve el GONE), en detrimento del Gran Oriente Español liderado por Miguel Morayta. La elección del GOI, una vez más, respondía a los intereses cosmopolitas de los integrantes, insertos en un entramado heterogéneo en cuanto a sus lugares de origen. Y es que también incluía logias portuguesas, hispanas, americanas e incluso marroquíes (de Tánger), con el propósito de hacer una «Confederación Íbero-americana» ${ }^{6}$, una actuación contraria al "españolismo» y "colonialismo» del GOE (Aguiar Bobet 2020b: 420-430), aunque también auspiciase logias

5 Carta de Luis Dugour a Francisco Rispá de Perpiñá, gran maestre del GOI. Expediente de Luis Dugour, CDMH c. 41 exp. 26.

6 Carta de Luis Dugour a Francisco Rispá de Perpiñá, gran maestre del GOI el 3 de julio de 1901. Expediente personal de Luis Dugour, CDMH c. 41 exp. 26. 
allende el Atlántico y el Mediterráneo. A principios del novecientos, con todo, el GOE acabaría siendo la única potencia masónica hispana, por lo que las logias canarias debieron circunscribirse a su jurisdicción. Más adelante, en 1923, con motivo de la reestructuración de dicha obediencia y con la creación de la Gran Logia Española -antigua catalano-balear- el paisaje masónico canario se modificaría, pero sin grandes cambios en las relaciones intermasónicas de los talleres, que, con todo, fueron cordiales en la mayoría de ocasiones ${ }^{7}$.

En cualquier caso, la institución de nuevas logias, cuyos móviles variarían entre el creciente número de iniciados y el abatimiento de columnas por el cambio de oriente, refleja otras tendencias interesantes: la necesidad de expansión y consolidación de la orden y de las redes entre sus miembros, pero también cómo se había conseguido cierta estabilidad en sus cuadros y composición. En otras palabras, cómo, de alguna manera, la sociabilidad masónica estaba respondiendo a las necesidades de sus integrantes. En este sentido, la relativa «especificación» de talleres, tal y como sucedía en otras regiones y épocas, no se observa con la misma clarividencia en las logias canarias. Manuel de Paz ha apuntado en diferentes ocasiones la heterogeneidad socio-profesional e ideológica de la membresía, como también se mostró en los datos ofrecidos supra. Si bien debían tener cierta formación e ideas liberales esenciales, no existió ningún taller con claras preferencias o tendencias más partidistas o clasistas (De Paz 1991: 340341), especialmente en aquellas que vivieron el azaroso siglo xix.

Respecto al resto de las logias peninsulares, americanas o extranjeras a las que pertenecieron los masones aquí tratados, cabe especificar que fueron: Fraternidad Ibérica de Madrid n 90 (GODE), Gran Oriente de Uruguay, Lealtad no 19 de Venezuela, Colón de Cuba, Hijos de la Fe Masónica en Sagua La Grande de Cuba, Cárdenas de la Gran Logia de la Isla de Cuba, Lazos de Unión de Cuba. Cuba, el territorio que muestra mayor representación, es un ejemplo más de la tendencia migratoria canaria. Aunque también cabría añadir Venezuela como parte de la misma tendencia, será la Gran Antilla quien acoja o de quien proceda la mayor parte del conjunto. Aun así, los garantes de amistad de las logias canarias con otras logias americanas que aparecen mencionados en los expedientes de los sujetos aquí tratados, también son una prueba de la conectividad diacrónica entre ambos espacios: Luis Dugour, garante de amistad con la logia Unanimidad no 3 de la Guaira, con Juan de la Cruz Enríquez no 246 y la logia Caracas no 16, las tres de Venezuela, así como la necesidad de mejorar las relaciones con las logias españolas de Filipinas, Buenos Aires y Tánger; o bien los contactos establecidos con el Gran Oriente de Venezuela por parte del venezolano José María Mendoza Pérez, otro de nuestros protagonistas, aprovechando los vínculos directos con su logia madre, Lealtad no 19 de La Guaira. Respecto a los talleres mencionados

7 A partir de 1923, la creación de la Gran Logia de las Islas Canarias sería, quizás, el acontecimiento más sustancial a este respecto, pero poco interfirió en la muestra analizada. 
de Uruguay e Italia, la red se establece también por la procedencia de dos de los componentes que se habían iniciado en sus países de origen.

Cabría preguntarse, con todo, si las logias en las que estuvieron o en las que se integraron entre las idas y venidas a Canarias, sobre todo en el caso de las americanas, estuvieron auspiciadas por algún oriente hispano, criollo o extranjero. La historiografía para el caso cubano, el más significativo de esta muestra, ha subrayado cómo españoles y criollos se adherían a unas y otras logias indistintamente, quizás atendiendo a lazos personales y profesionales, y no tanto a razones anti o pro emancipadoras (Torres Cuevas 2017: 58-64). Es más, aquellos masones como José Cabrera o del Socorro rápidamente se desligaron de la masonería para introducirse en otros grupos políticos que respondían con mejor eficiencia a sus intereses político-sociales.

Los masones canario-americanos, independientemente de su origen, nos ofrecen, en definitiva, la prueba irrefutable de la conexión migratoria constante, pero, sobre todo, las conexiones y solidaridades históricas y familiares, especialmente con Venezuela y Cuba, y, más que eso, las conexiones producidas por el imaginario cultural de la América española. La necesidad de los contactos, garantes y solidaridades entre los masones y los talleres canario-americanos, las idas y venidas y el continuo vínculo real y discursivo que mantienen formarían parte del imaginario aceptado y asumido por los actores: América había sido conquistada por los españoles, y los países latinoamericanos habían sido españoles. En cierto modo, también las jóvenes repúblicas en las que se convertirían eran herederas de la madre patria, lo que en ningún caso justificaba la mala gestión de la nación. El discurso que Ramón González del Socorro pronunció el 2 de diciembre de 1878 con motivo de la despedida hacia su logia Taoro no 90 de la Orotava, en el que legitimaría la guerra de Cuba a causa de la política colonial de España, es un gran ejemplo de ello, fundamentalmente porque todo el taller avalaría y aplaudiría sus palabras:

He llorado en países extranjeros las acerbas desventuras de mi patria; he trabajado en la medida de mis fuerzas por la consecución del fin grandioso que aquella revolución se proponía, y por más que repugna a mis principios la idea de la guerra, crimen perdonable cuando es la Razón la que a ella nos impele; por más que nunca el odio ha llegado a envenenar mis sentimientos con su maligno virus, yo, qq.: hh.:, obedeciendo a la voz de mi conciencia, impulsado por el más santo delos deberes, acepté con todas sus funestas consecuencias. (Ramón González del Socorro $1878^{8}$ )

Si bien Melitón Gutiérrez, José Cabrera Díaz y González del Socorro, por ejemplo, expresaron esta vinculación entre contextos ya relacionales de por sí, Luis Dugour añadiría a ello la preocupación del GOI, una de las dos obediencias que nacerían de la escisión del GONE, al fomentar los contactos con el Arte

8 Ramón González del Socorro a la logia Taoro no 90, 2 de diciembre de 1878. Expediente personal de Ramón González del Socorro, CDMH c. 580 exp. 19. 
Real de la otra orilla. El nombre de Gran Oriente Ibérico, en ningún caso, había sido baladí. El concepto de la hispanidad eludía en este caso a la pérdida de identidad colonial e imperialista de España y, por supuesto, al surgimiento de masonerías criollas nada relacionadas con la antigua patria. En estos momentos, el discurso cambiaría en favor de una comunidad relacionada históricamente por la presencia española, un tipo de lenguaje más neocolonial si se permite el anacronismo, pero que pretendía compensar la crisis emocional en la que se había sumergido la nación española después de la guerra de Cuba, y, por otro lado, el peso mayoritario que estaba obteniendo el GOE desde su formación con las logias hispanas del territorio nacional.

No obstante, si atendemos a otra variable, los nombres simbólicos elegidos, encontramos una puntualización a esta idea: el auge de otro imaginario, más regionalista y autonomista, pero no necesariamente antiespañol, ni contradictorio con la identidad de lo «hispano». En ocho casos, los pseudónimos provinieron de nombres canarios, sobre todo de los antiguos aborígenes de las Islas (Acaimo, Tinguaro, Taoro, Guanarteme [2]), que demuestran la importancia de las raíces isleñas y una creciente identidad histórico-comunitaria (Aguere -el nombre aborigen de La Laguna-, canario). En otros dos casos, respondían a la legitimación de la independencia de Cuba: José Cabrera Díaz, bajo el simbólico «Yara», también corrobora su actitud política y partidista, del mismo modo que Hatuey, seudónimo del cubano Tomás Acosta, miembro de la logia Taoro $n^{\circ}$ 90, «aquel cacique cubano caído por la conquista del territorio por los españoles» ${ }^{9}$.

Por otra parte, aunque ya hemos comentado algunas de las características masónicas de la muestra elegida, debemos analizar aquí los datos sobre la perdurabilidad en la orden de los actores de forma conjunta, especialmente para observar las tendencias de los protagonistas. En general, los 26 componentes estudiados se afilian a logias canarias o americanas en torno a los 30-40 años de edad, pero la duración dentro de la orden oscila en función de la trayectoria vital de cada uno. Cuatro de ellos apenas pasaron de los grados $1^{\circ}$ y $2^{\circ}$ en el Rito Escocés Antiguo y Aceptado y del Rito Francés (dependiendo de las obediencias y de las logias), durando su presencia aproximadamente un año. Un grupo de 8 constan con el grado $3^{\circ}$ hasta la obtención de sus planchas de quite o su irradiación (durando su permanencia entre dos y cuatro años), mientras que otros dos grupos que cubrirían los grados $11^{\circ}-18^{\circ}$ (6 individuos) y $24-33^{\circ}$ (8 individuos), perduraron alrededor de 7-30 años. Estos últimos, además, se iniciarían especialmente en la década de los 90 del siglo XIX o a principios del siglo xx. Lo que interesa de esta parte de la muestra son las razones por las que unos grupos acaban abandonando con prontitud su estancia en el Arte Real y, por el contrario, por qué los demás continuaron en la práctica de la masonería. Las historias de vida nos indican muchos de los factores que entraron en juego

9 Declaraciones hechas en Acacia no 4 el 21 de julio de 1932. Expediente personal de Tomás Acosta, CDMH c. 580 exp. 14. 
y que, sin duda, reflejan las diferentes funciones que tendría la orden para ellos o para el conjunto de la sociabilidad masónica. Por ejemplo, un porcentaje relativamente significativo de la muestra (20\%) se dio de baja en las logias canarias por su vuelta a Cuba, entre ellos, José Cabrera Díaz, González del Socorro o María Macías. Poco sabemos de sus andanzas masónicas posteriores, pero con cierta seguridad, primaron en sus vidas otros grupos y asociaciones de carácter ideológico-político más que el purismo y la moderación características del Arte Real.

En el caso de la mujer masona -cubana de origen y casada con otro miembro del taller (Azaña $\left.n^{\circ} 125\right)$, ambos de altos grados $\left(30^{\circ}\right.$ y $\left.33^{\circ}\right)-$, cabe mencionar su corta estancia por retornar también a Cuba, donde suponemos que continuarían su andadura en el Arte Real, dado los grados de los que disponían. No obstante, uno de los escasos documentos que se recogen en su expediente personal nos indica parte de su descontento hacia los proyectos del taller santacrucero, aconsejando que debían iniciar a «obreros más pobres pero ilustrados». No se cumpliría en ningún caso, pues, como ya han estudiado entre otros (González Fernández 2003: 110-116), el interés hacia la formación de los obreros y su inclusión en las logias se proyectaba mediante un discurso de absoluta convicción en el orden social y que en nada se relacionaba o abarcaba la situación real de las clases trabajadoras. José Cabrera Díaz, el más militante en este sentido, también intentaría promocionar iniciativas similares en el escaso cómputo de tiempo en el que anduvo en la misma logia que la mujer, Añaza no. 125. Su propuesta recaía en el apoyo económico a la Sociedad Germinalista de La Laguna en 1900 con 3 pesetas mensuales. La Biblioteca del Obrero, que antes mencionamos, en la que también participaría Espinosa, fue otra prueba de esta continua dicotomía entre el discurso y la práctica, en la que la masonería, como institución, parecía alejarse, no siempre así sus integrantes a título individual.

Sin embargo, existieron otros motivos por los que varios individuos de la muestra abandonaron las filas masónicas. El primero de ellos, Melitón Gutiérrez Castro, con apenas un año de haberse iniciado, sería expulsado de la orden. Había causado la muerte por accidente a una meretriz a finales de 1910. El incidente, del que quedaría absuelto de por parte de los «tribunales profanos», se convertiría en la excusa idónea para su irradiación por parte de un sector del taller, contrario a sus ideas revolucionarias en la prensa santacrucera, donde ponía en evidencia directamente a cierta élite de la capital relacionada con la logia Añaza, no 250 (bajo la obediencia del GOE). Ni siquiera los contactos en las altas esferas de la orden en Canarias pudieron hacer nada por modificar el veredicto, como señalamos en el apartado anterior. Gutiérrez no volvería a pisar el Arte Real, ni siquiera, una vez que se traslada a Las Palmas de Gran Canaria. Además, volvería a ser procesado en otras ocasiones por sus artículos periodísticos y sus actividades políticas.

Otro individuo, Antonio García González, miembro de Añaza no 270 también manifestaría su descontento con el resto de los miembros del taller por no haberle ayudado a encontrar un trabajo en la capital, añadiendo a las 
quejas «y eso que el alcalde es masón» ${ }^{10}$. Declararía también que, en su andadura masónica en Cuba, previa a la tinerfeña, había recibido todo tipo de apoyo de sus hermanos, contrastando así con la escasa eficacia de la red canaria, una red que debía servir como apoyo mutuo entre cofrades. En esta misma línea discurría otro de nuestros protagonistas, José María Alonso Gutiérrez, quien apuntaría su decepción hacia la sociabilidad masónica en función de sus intereses. De hecho, será uno de otros tantos masones que, con motivo de la guerra, se adherirían rápidamente el «Glorioso Movimiento Nacional» de Franco. El caso de Cándido Alarcó Aznar, originario de Cuba, también es significativo de tal desencanto, pues especifica en su solicitud de baja del taller Añaza que solicita su «plancha de quite irrevocable por entender que la logia debe trabajar por el progreso moral e intelectual» ${ }^{11}$. El enunciado hacía referencia a las disputas entre los nuevos iniciados o afiliados y el «elemento antiguo» del taller, por la conducta que debían seguir, y que no siempre era la adecuada, según los preceptos de la orden (De Paz 2008 vol 2: 65). Constan, a su vez, otros cuatro miembros de la muestra irradiados o dados de baja "por falta de pago», sin especificar otra razón, probablemente porque habían dejado de asistir a las reuniones y de pagar las cuotas.

De todos modos, tal y como apuntamos a través de los datos sobre la permanencia de los iniciados o afiliados en la masonería, un grupo mayoritario continuaría en sus filas y ascendería de grado. Patricio Estévanez y Murphy, por ejemplo, continuaría en el Arte Real durante varias décadas, al igual que Luis Dugour, Silvio Montero o José Ruíz Rodríguez. Habría que definir y comprobar, en este sentido, los móviles que los llevarían a continuar o a solicitar la plancha de quite. En algunos casos, con la muerte de por medio, no existieron motivos aparentes de ninguna desilusión, salvo aquellos que, por motivos de falta de pago, sus familias no recibieron el auxilio de la orden, el denominado Montepío masónico. La guerra civil fue el final para los que continuaron durante la época republicana, ya fuese porque tuvieron que emigrar a América, retornar a sus diferentes países, o ser procesados por el nuevo régimen. Pero estos son los menos cuantiosos en la muestra.

\section{Conexiones y desconexiones a partir de los actores}

La muestra seleccionada, como hemos visto hasta el momento, presenta numerosas posibilidades de análisis a partir de los datos, informaciones y discursos focalizados en los actores. No obstante, para obtener resultados más sustantivos, que puedan contrarrestar algunas de las valoraciones apriorísticas aquí señaladas, se torna preciso ampliar la muestra en futuros trabajos, tanto

10 Declaración retractación prevenida de 1948 de Antonio García González. Expediente personal, CDMH c. 36 exp. 5.

11 Solicitud de plancha de quite irrevocable a su logia, Añaza $n^{\circ} 125$, el 4 de junio de 1904. Expediente personal, CDMH c. 38 exp. 14. 
de forma diacrónica como sincrónica, además de seguir la trayectoria de los actores, dentro y fuera de la masonería. En todo caso, y gracias a esta primera aproximación, en este último apartado queremos hacer una pequeña reflexión sobre los ítems valorados, sobre los puntos de encuentro y desencuentro entre los protagonistas, es decir, aquellas conexiones o desconexiones que percibieron y experimentaron desde la masonería, desde Canarias y desde América, pues fueron aquellos espacios en los que se produjeron las prácticas de sociabilidad y las redes interpersonales y sociales mencionadas.

En primer lugar, gracias a las migraciones históricas y a las identidades compartidas en los procesos de resignificación identitaria por la pérdida de las colonias americanas (tanto de un lado como de otro), Canarias y América, como contextos relacionales, quedan expuestas en los numerosos vínculos, viajes, idas y vueltas entre las Islas y, principalmente en Cuba. En este sentido, el estudio de los individuos no solo deja constancia de la tendencia, sino de la cercanía simbólica, casi familiar, entre las dos orillas del Atlántico, una vinculación que parecía más potente en la aceptación e inclusión de masones latinoamericanos que de otros ámbitos de la Península, como en el caso de Melitón Gutiérrez. América, en su multitud de significantes, sería para los masones de las logias canarias un tema constante, ya fuese por la participación en las guerras de emancipación, por sus posturas contrarias al autonomismo o al nacionalismo cubano, o por la necesidad de configurar un oriente ibérico que recompusiese el orgullo nacional perdido después del noventa y ocho. A pesar de que el tratamiento de la guerra de Cuba varió en función de los individuos, y aunque las obediencias hispanas, por lo general, avalaron la guerra en su más sentido patriotismo español (Castellano Gil 1996: 52), en el conjunto aquí tratado parece primar el apoyo hacia las vindicaciones nacionalistas de la Gran Antilla, vindicaciones que también traspasaron el modelo autonomista canario. Lo que sí resultaría unánime sería la crítica y la denuncia a la actuación de España en tales procesos y el paso de una concepción imperialista-colonial de los países latinoamericanos y su relación con la madre patria a la construcción de una identidad común que se empezaba a sustentar en lazos históricos y simbólicos, y no tanto de pertenencia; lazos expresados en las continuas migraciones desde ambas orillas, en la insistencia en la mejora y asiduidad de los contactos entre las logias, mediante el concepto de lo «ibérico» y de la «hispanidad» e, incluso, en la participación en diferentes asociaciones, periódicos y grupos políticos constituidos en Cuba.

En segundo lugar, la masonería, como institución formalizada, pero también como espacio de sociabilidad en la que se conforman redes sociales y de solidaridad interpares, paralela a otras ofertas asociativas, es percibida por los protagonistas de forma instrumentalizada, casi personalizada. Por un lado, a nivel institucional se comprendía el Arte Real español como un baluarte de los intereses de la nación, especialmente en relación a América y la pérdida de las últimas colonias de Ultramar, pero, por otro, se asume como espacio en los que se aprenden valores esenciales y se afianzan redes efectivas, muchas veces 
nada relacionadas con los fines de la masonería. Una masonería que estaría más enfocada hacia un ámbito discursivo/simbólico y de intereses interpersonales que hacia cambios sociales realmente significativos, tanto en el contexto sociopolítico como en la situación de sus miembros o de las demandas planteadas. Por ejemplo, al respecto de la emancipación real de los obreros, el apoyo a la Sociedad Germinalista, a la Biblioteca de El Obrero o la inclusión de los trabajadores medios en las filas de la orden. De hecho, la correspondencia, los discursos de los individuos y la perdurabilidad de sus experiencias masónicas muestran que se comprendía más bien como un medio para conseguir enlaces locales, nacionales y globales que como un instrumento para difundir ideas políticas e ideologías; una masonería que también se conformaría como una sociedad «de paso» o de introducción a las élites locales para los viajeros e inmigrantes. Por ejemplo, si nos ceñimos a los discursos leídos en las reuniones, la ciega convicción en los preceptos y funciones de la orden sería el lenguaje predominante: «La civilización profana no puede estimar cuanto le debe el mundo a la masonería, por desconocer su obra. Es el centro por excelencia de unión, de libertad y de progreso entre todos los hombres, entre todas las naciones, entre todas las religiones y entre todas las épocas» ${ }^{12}$.

No obstante, la ambivalencia que plantean los discursos a través de la correspondencia y las prácticas de los actores nos ha llevado a enriquecer las conclusiones y valoraciones de la muestra, y a dibujar un paisaje más fiel a la realidad relacional y compleja del pasado. Es decir, los vínculos masónicos configurados se basaban en lazos que se daban por sentados (los preceptos del Arte Real) y que, en pocas ocasiones, serían efectivos en sí mismos. De ahí, la inconsistencia de las redes masónicas al final, su volatilidad o escaso rastreo temporal en la trayectoria vital de algunos actores. Las redes establecidas y las sociabilidades producidas en muchos casos no llegaron a ser duraderas, sino anecdóticas (pocos años o con numerosas interrupciones). Al no producir efectos económicos ni la ayuda mutua esperada, aquellas solidaridades efectivas, más allá del ámbito discursivo y las parafernalias inherentes a la práctica de la masonería en cuanto a asociación (con sus códigos normalizados de actuación, verbalización y lenguaje corporal), hacían que los actores abandonaran el escenario de la orden. En otras palabras, al no producir una confianza real (basada en efectos y resultados reales), muchos de los participantes, al principio más utópicos y esperanzadores con las posibilidades de la orden, se esfumarían, decepcionados o desencantados, tal vez, de la masonería. Buscaban y esperaban apoyos y solidaridades, por lo general, no como un punto en común o de enlace para acceder a otras asociaciones o grupos, como sucedía en otras regiones (Sala 2010: 10-14), sino como un apoyo directo, esperado y deseado, dados los mensajes simbólicos y los preceptos masónicos. De ahí, también, que la mayor parte de los personajes más radicales o más interesados en ciertos fines (fuesen

12 Discurso de Ángel Possentini para una tenida de iniciación de la logia Añaza no 125 el 4 de diciembre de 1903. Expediente personal, CDMH c. 48 exp. 2. 
personales, migratorios, políticos, nacionalistas o ideológicos) rápidamente abandonasen sus filas para continuar por otras vías más adecuadas o eficaces para conseguirlos. Y al contrario, aquellos más moderados o que buscaban cambios menos sustanciales en el ámbito social, es decir, que estaban más ceñidos al orden establecido y cuyas redes localistas-masónicas respondían a sus fines, adquiriesen grados más elevados en la orden o, al menos, su estancia en la masonería acabaría siendo más larga y duradera. De todos modos, este tipo de solidaridades y desencantos son bastante comunes en la masonería española, al menos en las que hemos podido estudiar en otros paisajes históricos, tal y como planteamos en nuestra tesis sobre la masonería española en Marruecos durante el periodo republicano (Aguiar Bobet 2020a: 1190-1198).

\section{Epílogo}

La importancia de este tipo de estudios «relacionales» y focalizados en los actores, en sus trayectorias diacrónicas y sincrónicas, viene determinada por su capacidad para calibrar redes más amplias y prácticas sociales más complejas. Permite, además, observar un entramado sutil de lenguajes sociales, tanto para comprobar sus interrelaciones, eficacias, solidaridades, decepciones, etcétera, como su verdadera proyección, tal y como la percibieron sus protagonistas. Sin embargo, esta investigación es solo una primera aproximación que pretende sentar las bases para otros estudios futuros y servir de debate a priori sobre aquellos aspectos teórico-metodológicos establecidos y los resultados de la muestra elegida. El análisis relacional, esto es, el análisis de lo concreto y de lo global de una muestra determinada, y desde el punto de vista de los sujetos, permite enriquecer la historia y su epistemología; una historia que, a su vez, permite observar los vínculos entre diferentes esferas y diferentes contextos, como en el artículo aquí expuesto: la percepción de Canarias como espacio intermedio, simbólico para los actores, al igual que la masonería. En este sentido, la historia relacional y conectada que pretendimos configurar es una historia global porque al seguir a los actores que conectan, en la práctica, diferentes espacios, nos acerca al modo en que estos espacios se afectaron mutuamente. Desde esta línea, además, se pudo comprobar que la correspondencia y las relaciones inter-masónicas no son locales, ni nacionales, ni mundiales, sino que forman parte de una historia conectada; una historia conectada que, al aunar, de algún modo, estas tres vertientes -en la medida en que los actores interactúan simultáneamente en ellas-, las conectan y producen una historia específica y diferenciada (Imízcoz 2018: 57-60).

Gracias a este tipo de análisis relacional, se comprueba, por tanto, cómo la masonería fomentó las "situaciones de contacto», la red de cartas institucionales y privadas, las redes sociales e intereses de todo tipo: a partir de las fuentes epistolares transatlánticas y de todos los documentos generados por sus partícipes en la orden, se pudo analizar la diversidad de funciones que asumen, los lazos de cooperación, solidaridades, tensiones..., pero también cómo se 
intercambian, se negocian y se difunden ideas y percepciones. Esta primera investigación ha logrado mostrar así que la circulación entre ellos es mucho más rica e intensa de lo que se había creído, al menos más de lo que puede permitir el análisis exclusivo y objetivo de las redes. Y ha sido metodológicamente global porque los actores, al actuar simultáneamente en diversas esferas (la economía, la política, la sociedad, la cultura, la masonería), las conectan y, de este modo, revelan cómo esas esferas se relacionan entre sí. En otras palabras, cómo lo político, lo económico, lo societario y lo cultural se interrelacionan en cada momento, en cada lugar, no de forma teórica, a priori o predeterminada, sino por los mismos agentes que actúan simultáneamente en diversos campos, instituciones y espacios.

En este sentido, el alcance global de la masonería por medio de los numerosos individuos que se insertaron en sus logias muestra la capacidad globalizante y camaleónica de la orden, su repercusión sociopolítica en los diferentes contextos relacionales y su función como alternativa asociativa, como enlace entre zonas y personas con valores y deseos comunes y que produjeron nuevas formas de sociabilidad dentro de las logias y entre diferentes talleres. Y todo ello pese a que no siempre perdurarían en las filas del Arte Real el tiempo suficiente (por las decepciones mencionadas $\mathrm{u}$ otros motivos político-ideológicos, como la represión de la orden en España). Es más, los que disfrutaron de redes masónicas más consolidadas, contactos en las altas esferas del poder local, regional o nacional y posturas ideológicas más moderadas permanecieron durante más tiempo en la masonería y se beneficiaron de sus condiciones socio-políticas. Otros varios, sin embargo, tendieron a estar poco tiempo, a desencantarse y a buscar nuevas redes y posibilidades, independientemente de la época y de la zona. La masonería canaria, aunque se comportó, en definitiva, como una vía de introducción social, de solidaridades y apoyo mutuo para sus componentes, también dejaría de ser factible para ellos en el momento en que no pudo responder a sus diferentes intereses y demandas personales.

\section{Bibliografía}

Aguiar Bobet V., 2014, «Seis horas en campaña: apuntes de un soldado español en Cuba», Ibero-Americana Pragensia, Supp, Praga, p. 175-185.

Aguiar Bobet, V., 2018, «Redes masónicas epistolares entre Marruecos, México y Cuba durante la segunda República española», REHMLAC+10, n. ${ }^{\circ} 1$, p. 56-92, $<$ https://doi.org/10.15517/rehmlac.v10i1.32432>, consultado el 35/03/2020.

Aguiar Bobet V., 2020a, La masonería española en Marruecos: un proyecto colonial (1881-1936), tesis doctoral, Universitat Jaume I.

Aguiar Bobet V., 2020b, «La masonería española en Cuba y Marruecos: ideales, imaginarios y utopías coloniales», Revista de Indias-CSIC, vol. LXXX, n. ${ }^{\circ}$ 279, p. 415-446. 
Agulhon M., 1977, Pénitents et Francs-Maçons de l'ancienne Provence. Essai sur la sociabilité méridionale, Paris, Armand Colin.

Agulhon M., 1988, Histoire vagabonde I. Ethnologie et politique dans la France contemporaine, Paris, Gallimard.

Beaurepaire P.-Y., 1999, La république universelle des francs-maçons. De Newton à Metternich, Rennes, Ouest-France.

Beaurepaire P.-Y., 2013, «Sociabilidad y Francmasonería. Propuestas para una historia de las prácticas sociales y culturales en el Siglo de las Luces», REHMLAC+ 5, n. ${ }^{\circ}$ 1, p. 2- 13.

Beaurepaire P.-Y., Taurisson D., 2003, Les Ego-documents à l'heure de l'électronique. Nouvelles approches des espaces et réseaux relationnels, Montpellier, Publications de Montpellier III.

Bloch M., 1952, Introducción a la Historia, México, Fondo de Cultura Económica. Bryon-Portet C., 2013, Sociologie de sociétés fermées. Imaginaire symbolique et sacralité en milieu clos, Montpellier, Presses universitaires de la Méditerranée.

Castellano Gil J.M., 1996, Masonería Española en Cuba, La Laguna, Ayuntamiento de San Cristóbal de La Laguna.

De Paz Sánchez M. 1991, «La francmasonería decimonónica en Tenerife: la logia Nueva Era, número 93 de La Laguna», Anuario de Estudios Atlánticos, n. ${ }^{27}$, p. 309-342.

De Paz Sánchez M. 2004, «Masonería e independencia de Cuba en 1878: el caso de la logia Taoro de la Orotava», Revista de Historia Canaria, n. ${ }^{\circ}$ 186, p. 265-275.

De Paz Sánchez M. 2006a, «Masonería española y emancipación colonial», Revista de Indias, vol. 66, n. ${ }^{\circ} 238$, p. 737-760.

De Paz Sánchez M. 2006b, La masonería y la pérdida de las colonias, Santa Cruz de Tenerife, Ediciones Idea.

De Paz Sánchez M. 2007, «El Jardín de la Virtud (la masonería como una disidencia cristiana del XIx)», Anuario de Estudios Atlánticos, n. ${ }^{\circ}$ 53, p. 299336.

De Paz Sánchez M. 2008, Historia de la francmasonería en Canarias (1739-1936), 2 tomos, Santa Cruz de Tenerife, Ediciones Idea.

De Paz Sánchez M. 2009, «Identidades lejanas. El proyecto nacionalista canario en América (1895-1933)», Catharum, n. ${ }^{\circ}$ 10, p. 43-70.

De Paz Sánchez M. 2018, «El curioso impertinente. Vida, pasión e incógnitas de Melitón Gutiérrez Castro, autor de Los incognoscibles», Revista Digital Cuatrimestral de la Academia Canaria de la Lengua, n. ${ }^{\circ}$ 13, Santa Cruz de Tenerife y Las Palmas de Gran Canaria, <http://aclrevistaliteraria. academiacanarialengua.org/el-curioso-impertinente>, consultado el $17 / 04 / 2020$.

De Paz Sánchez M. , Luis León D., Aguiar Bobet V., 2020, «Bibliotecas Populares en Canarias: la Biblioteca de El Obrero», en prensa. 
González Díaz J.F., 2010, «José Cabrera Díaz, un canario al servicio de Cuba», XIX Coloquio de Historia Canario-Americana, Las Palmas de Gran Canaria, $<$ http://coloquioscanariasamerica.casadecolon.com/index.php/CHCA/ article/view/9046>, consultado el 01/01/2020.

González Fernández A., 2003, «Masonería y modernización social: la transformación del obrero en ciudadano (1868-1931)», Bulletin d'Histoire Contemporaine de l'Espagne, n. ${ }^{\circ}$ 32-36, p. 89-116.

Harland-Jacobs J., 2014, «Freemasonry and Colonialism», in Bogdan H., Snoek J.A.M. (eds.), Handbook of Freemasonry. Brill Handbooks on Contemporary Religion, vol. 8, <https://doi.org/10.1163/9789004273122>.

Harland-Jacobs J., 2017, «Fraternidad global: masonería, imperios y globalización», in Martínez R., Pozuelo Y. y Aragón R. (eds.), 300 Años: masonerías y masones. Cosmopolitismos, t. 5, México, Palabra de Clío, p. 65-93.

Hobsbawm E., 1983, Rebeldes primitivos, Ariel.

Imízcoz Beunza J.M., 2018, «Por una historia global. Aportaciones del análisis relacional a la Global History», in Ibarra A., Alcántara A. y Jumar F. (coords.), Actores sociales, redes de negocios y corporaciones en Hispanoamérica, siglos XVII-XIX, Méxixo, UNAM, p. 27-60.

Imízcoz Beunza J.M. y Arroyo Ruiz L., 2011, «Redes sociales y correspondencia epistolar. Del análisis cualitativo de las relaciones personales a la reconstrucción de redes egocentradas», REDES 21, n. ${ }^{\circ} 2$, p. 98-138, <http://revistes.uab.cat/ redes/article/view/419>, consultado el 04/05/2020.

Martín Martínez L.P., 2003, «Las logias masónicas: una sociedad pluriformal», Hispania: Revista española de historia, vol. 63, n. ${ }^{\circ}$ 204, p. 523-550.

Martínez Esquivel R., 2016, «Prosopografía y redes sociales: notas metodológicas sobre el estudio de la masonería en Costa Rica», REHMLAC+ 7, n. ${ }^{\circ}$, p. 1-27, <https://doi.org/10.15517/REHMLAC.V7I2.22689>, consultado el 10/04/2020.

Martínez Esquivel R., 2018, «Global History and Freemasonry: 300 years of Modernity, Sociability and Imperialism», REHMLAC+ 9, n..$^{\circ} 2$, p. 1-18, $<$ https://doi.org/10.15517/rehmlac.v9i2.31496>, consultado el 03/02/2020.

Mollés D., 2013, «Triangle atlantique et triangle latin: l'Amérique latine et le système-monde maçonnique (1717-1921)», REHMLAC+5, n. ${ }^{\circ} 1$, p. 188-196, <http://rehmlac.com/recursos/vols/v5/n1/rehmlac.vol5.n1-dmolles.pdf>, consultado el 25/05/2020.

Oliveira Marques A.H., 1983, A Maçonaria Portuguesa e o Estado novo, Lisboa, Publicaçoes dom Quixote.

Pomares F. y Aguiar Bobet V., 2017, Cuba en el horizonte. Selección de textos de la emigración (1833-1941), 2 tomos, Santa Cruz de Tenerife, Ediciones Idea.

Sala C., 2010, «La sociabilidad masónica francesa en la encrucijada de las fronteras fraternales y profanes: el ejemplo de la ciudad de Perpiñán en el siglo XVIII», REMLAC+ 1, n. ${ }^{\circ}$ 2, p. 3-16. 
Saunier E., 2017, «El espacio caribeño: un reto de poder para la masonería caribeña», in Martínez R., Pozuelo Y., Aragón R. (eds.), 300 años: masonerías y masones, tomo I: Migraciones (1717-2017), México, Palabra de Clío, p. 76-90. Simmel G., 1999, Sociologie. Études sur les formes de la socialisation, Paris, PUF. Thomson E. P., 1989, La miseria de la teoría, Barcelona, Crítica.

Torres Cuevas E., 2017, «Masonerías en Cuba durante el siglo XIX», in Martínez R., Pozuelo Y. y Aragón R. (eds.), 300 años: masonerías y masones, tomo I: Migraciones (1717-2017), México, Palabra de Clío, p. 46-75. 